\title{
VARIACIONES PRAGMÁTICAS DEL DISCURSO ELECTORAL: EL CASO DE "HOPE" DE BARACK OBAMA ${ }^{1}$
}

\author{
Manuel Balsera Fernández, Universidad de Córdoba (España) \\ Email: MBALSERAF@terra.es
}

\begin{abstract}
Resumen: En este artículo nos proponemos examinar el cartel "HOPE" de Barack Obama, entendido como un discurso electoral icónico-verbal y artístico a la luz de la Teoría de la Relevancia de Sperber \& Wilson (1986, 1995, 1998, 2002; Wilson \& Sperber 2002; Sperber \& Wilson, 2012) considerada como una de las más fructíferas para estudiar la transmisión de mensajes comunicativos multimodales. Para su descripción, análisis e interpretación recurriremos al concurso de otras disciplinas y, fi nalmente, trataremos de establecer un diálogo ecoico-orquestal con otras representaciones mentales de naturaleza política y propagandística no afín como réplicas culturales del original.

Palabras clave: Pragmática, Relevancia, Modularidad, Publicidad Política, Barack Obama, Representaciones Paródicas y Violencia.

Title in English: Pragmatic variations of electoral discourse: The poster "Hope" of Barack Obama

Abstract: The aim of this paper is to examine the Poster HOPE of Barack Obama's election campaign in the light of Relevance Theory (Sperber \& Wilson 1986, 1995, 1998, 2002; Wilson \& Sperber 2002; Sperber \&Wilson 2012) considered a helpful methodology in order to study the transference of multimodal communicative messages. The poster HOPE merges a set of graphic and symbolic components together with the text so that it makes up an electoral speech. We count on the contributions of other disciplines that describe, and interpret the poster in a relevant way. We then compare it with other cultural echo-representations of electoral products and negative political propaganda, as replicas of the original.

Keywords: Pragmatics, Relevance, Modularity, Political Advertising, Barack Obama, Political Parody and Violence.
\end{abstract}

\section{INTRODUCCIÓN}

El póster que hemos seleccionado como objeto de estudio representa sólo una parcela minúscula de lo que se ha venido en llamar publicidad viral o epidemiología de las representaciones por su forma de propagación en canales tan heterogéneos como Internet

\footnotetext{
${ }^{1}$ Date of reception: 5 May 2012

Date of acceptance: 5 August 2012
} 
y otras tecnologías de vanguardia, permitiendo a las personas crear y compartir contenidos de su interés.

La fi gura de Barack Obama es un producto de singular importancia del marketing político estadounidense desde el inicio del 2008. Para esa fecha, el artista Shepard Fairey ya había creado este famoso afi che que muestra en tonos azules y rojos el rostro de Obama, en actitud de liderazgo, manteniendo la mirada ${ }^{2}$ alta y como entreviendo el futuro. En la solapa de su chaqueta aparece su distintivo personal (logo) y, ocupándole la zona del pecho, con una tipografía novedosa la palabra "HOPE"3, la más repetida en sus eslóganes electorales.

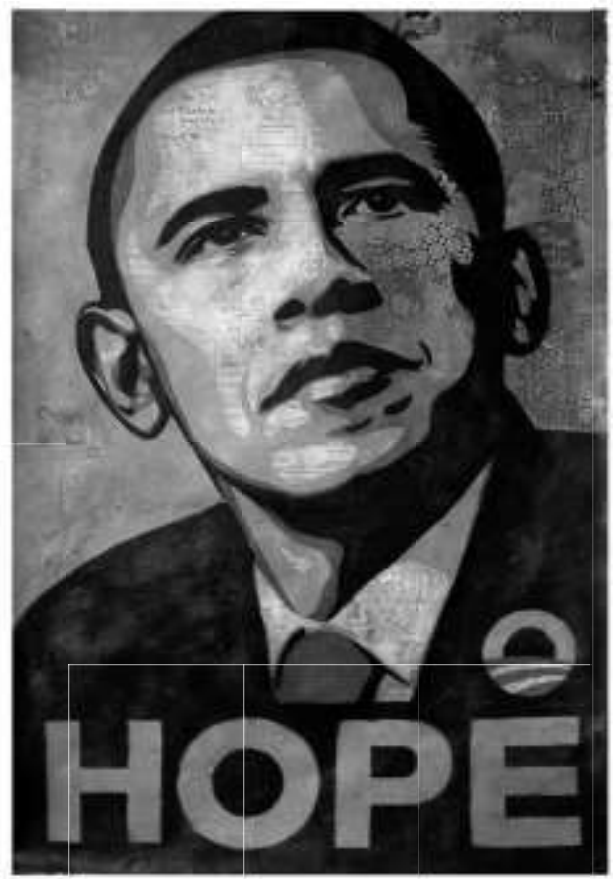

Dan Sperber y Deirdre Wilson dieron a conocer por primera vez la Teoría de la Relevancia en su libro Relevance: Communication and Cognition (1986) y han continuado desarrollándola tenazmente, en trabajos posteriores, hasta la actualidad más reciente, Meaning and Relevance (2012). La teoría de la Relevancia proporciona un aporte importante a la comprensión del fenómeno de la comunicación humana. Los autores se posicionan entre los modelos que inscriben la interpretación de enunciados dentro de la Psicología Cognitiva, enfocando el problema de la comunicación desde la capacidad

\footnotetext{
${ }^{2}$ El ser humano dedica una gran parte de su tiempo a aventurar posibles signifi cados a las miradas de los demás, sobre todo porque la mirada puede invalidar, reforzar o modifi car el signifi cado de los enunciados verbales. Yus Ramos (1997:322)

${ }^{3}$ En el otoño del 2006 Barack Obama publica un libro de memorias titulado The audacity of Hope -traducido y publicado en español en el año 2007 por la editorial Península con el título La audacia de la esperanza; en las ideas contenidas en él se basa este eslogan de campaña.
} 
cognitiva de los seres humanos. Los contextos adquieren de esta forma un marcado carácter psicológico que apela a la activación de esquemas emotivos -schemata- en relación con conocimientos experienciales -background knowledge-. Estas capacidades cognitivas son, esencialmente, meta-representaciones del receptor. Por otra parte, Dan Sperber sostiene que la cultura está constituida por ideas contagiosas y, por consiguiente, considera que explicar la cultura es explicar por qué y cómo existen ideas contagiosas. La visión de la cultura que Sperber defi ende es, a la vez, epidemiológica ${ }^{4}$ y cognitiva. En este estudio de caso trataremos de conciliar interactivamente la transdisciplinariedad y los tres grandes conceptos de la Teoría de la Relevancia en sus aspectos cognitivos y antropológicos: el de representación mental (mental representation), el de representación pública (public representation) y el de representación cultural (cultural representation).

K. Tanaka, basándose en la teoría de la Relevancia, nos habla en su libro Advertising Language (1994) sobre la transmisión de información encubierta ${ }^{5}$. Ésta se produce cuando la manifestación mutua (mutual manifestness) entre emisor-receptor es débil, defi niéndola como un medio opuesto a la comunicación ostensiva. Por esta razón analizaremos brevemente algunos ejemplos de humor gráfi co-político y algún caso de metalepsis grafi coverbal producida por la adición sucesiva de mensajes sobre el cartel objeto de estudio.

Para elaborar una aproximación al estudio del fenómeno paródico y contrapublicitario del póster consideraremos los trabajos de diversos investigadores del Mental Research Institute de Palo Alto, California, USA que, nutriéndose de las contribuciones del antropólogo Gregory Bateson y de otros científi cos de disciplinas diversas, fueron perfi lando un enfoque pragmático de la comunicación humana, centrado ya no en el estudio de las condiciones ideales de comunicación (modelo del código de Shanon y Weaver ${ }^{6}$ ) sino en la investigación de la interacción personal, tal cual se da de hecho entre los seres humanos, repleta de infl uencias recíprocas, de disfunciones y "patologías" que, aplicadas al tema político que nos ocupa, consideramos que estarían constituidas, entre otras, por los prejuicios sociales y cognitivos, la distorsión de la información, por las estratagemas de la dialéctica erística o la violencia simbólico-institucional, así como, fi nalmente, por las paradojas del sistema electoral. Este enfoque recibió el apelativo de "modelo orquestal de comunicación": todo cuanto acontece en una situación de interacción adquiere valor comunicativo. Los actores de la comunicación construyen su diálogo y, por ende, se autoerigen en miembros de una comunidad cultural.

\footnotetext{
${ }^{4}$ El término antropológico de epidemiología sociocultural pretende asumir como objeto de estudio los procesos dinámicos que incluyen las respuestas individuales y sociales. Esta dinámica de estudio concede un papel activo al investigador como intérprete viral. Para nosotros el libro de Dan Sperber Explaining Culture: A Naturalistic Approach (1996) constituye un hito en esta línea de investigación.

${ }^{5}$ Como su propio nombre indica, la comunicación encubierta se asienta en la idea de que el emisor no expresa su intención comunicativa de forma explícita sino que otorga un papel relevante al receptor en tanto que le responsabiliza de la activación de presuposiciones y, sobre todo, de implicaciones débiles que dependen únicamente de él.

${ }^{6}$ Claude E. Shannon presentó su célebre trabajo A Mathematical Theory of Communicationen 1948. Un año más tarde, en colaboración con Warren Weaver, vio la luz The Mathematical Theory of Communication. Multitud de trabajos posteriores han demostrado que el modelo de código es insufi ciente para explicar, entre otras cosas, el papel de gran responsabilidad que tiene el receptor en la activación de inferencias.
} 
Y fi nalmente, queremos delimitar nuestra posición como intérpretes harto diferente de la del receptor primigenio, porque en una situación de comunicación secundaria pueden cambiar y, con frecuencia cambian, los contextos. En un discurso dado, hablar en otra lengua puede no tener implicaciones razonadas distintas, pero sí contextuales. Consideramos que la distancia cultural que nos separa, desde unos hábitos políticos electorales diferenciados, nos permite adoptar una posición de cierta neutralidad analítica, que es la que debe asumir el traductor como lector-intérprete, en esta otra comunicación de segundo orden. Por ello utilizaremos tanto las representaciones como los enunciados de forma descriptiva pero también de forma interpretativa, como sugiere López Folgado (2010:53): "La forma interpretativa se lleva a cabo en virtud de las semejanzas con otras representaciones. Tenemos por ejemplo las citas directas o indirectas, la ironía, la metáfora y otros usos ecoicos". En nuestra opinión, presuponemos que las representaciones paródicas del cartel son usos distorsionados y ecoicos del original.

Con el fi $\mathrm{n}$ de orientarnos con rapidez en nuestro itinerario nos plantearemos la siguiente cuestión: ¿Qué ocurre cuando la imagen corporativa (el cartel electoral), la obra artística (el cartel en el museo) y el texto interaccionan para conformar un mensaje electoral específi co a la manera del modelo orquestal de comunicación de Palo Alto? ${ }^{7}$ Ocurre, a nuestro entender, que se ha creado un texto multimodal ${ }^{8}$ que, sin lugar a dudas, ha supuesto un proceso de construcción global u holística desarrollado como un producto cultural calculado centrado en el "YO" político como representación pública ${ }^{9}$. Ocurre también que, al considerar en nuestro estudio un corpus de representaciones paródicas y contrapublicitarias del mismo cartel, deberemos orientar nuestra indagación en el proceso de comunicación según los niveles de complejidad, de contextos múltiples y de sistemas que pueden presentar rasgos de cierta circularidad, tal y como trataremos de mostrar más adelante. Asimismo, ocurre algo muy distinto a la transmisión accidental de información, a los errores de comprensión y a la imposibilidad de comprensión del mensaje por parte de la audiencia. Nos encontramos ante un caso que responde al modelo de comunicación ostensivo-inferencial que permite el paso del signifi cado literal a la interpretación pragmática de los mensajes mediante un mecanismo deductivo que se apoya en variados procesos y estrategias. La "ostensión (de ostendere, mostrar) consiste en ir guiando el proceso inferencial del receptor, de modo que éste no se vea obligado a derivar información a ciegas, sino cómo y dónde el hablante le indique" (Pons Bordería, 2004). Nosotros afi rmaríamos que el receptor deriva la información relevantemente como metarrepresentación.

\footnotetext{
${ }^{7}$ Los estudiosos más conocidos del modelo de Palo Alto son Gregory Bateson, Edward Hall, Paul Watslawick y Erving Goffman.

${ }^{8}$ El concepto de modalidad entendido como un operador que actúa sobre toda la comunicación. Supone la expresión de la actitud del hablante ante todo lo que informa (Catalina Fuentes Rodríguez)

${ }^{9}$ La publicidad electoral es un producto cultural sofi sticado y calculado tanto en la estructura del mensaje como en su procedimiento de transmisión. No debemos perder de vista que el paso de lo mental a lo público, en los medios clásicos, sólo puede darlo quien tiene poder, es decir, quien domina la comunicación y tiene voz para difundir sus representaciones mentales. La aparición del fenómeno del ciberespacio, los blogs o bitácoras, las redes sociales y la telefonía móvil han modifi cado de manera sustantiva y revolucionaria este aserto.
} 


\section{El modelo escripto-icónico aplicado al cartel}

Yus Ramos (1997), partiendo de la Teoría de la Relevancia, elabora una propuesta metodológica integradora capaz de establecer vínculos entre el sistema verbal y el no verbal en un mismo discurso. Mantiene que su modelo tiene un carácter armonizador y trata de reunir diferentes posibilidades comunicativas e interpretativas en 16 supuestos para taxonomizar la denominada fase de incertidumbre que se produce entre la producción de un mensaje y la evaluación de su relevancia. Para ello hay que resolver dos enigmas básicos en comunicación: a) la adscripción de intenciones y b) la identifi cación de la interpretación que busca el emisor. Este autor asume la realidad de la pragmática como un mosaico disciplinar en el que tienen cabida numerosas orientaciones y aproximaciones al estudio del lenguaje en uso. Este autor considera que su modelo puede adaptarse a diferentes tipos de discursos.

El cartel electoral, debido a su fi jación en un soporte físico, posibilita un estudio de las unidades y de las relaciones que lo vertebran. Puede ser incluido dentro de la categoría de comunicación dialógica en la que no se da la co-presencia del emisor-receptor. El comunicador ha de valerse de subterfugios dialógicos propios del discurso publicitario electoral. Uno de ellos es el anclaje o asociación automática entre el estímulo y la respuesta emocional. Este proceso se produce a través de los sentidos y constituye un importante aspecto de la relación texto-imagen: la imagen puede "anclar" el texto (anclaje icónico) y éste a su vez puede "anclar" la imagen (anclaje textual). En síntesis, el anclaje visual lo componen la marca Obama y su proyección escrita $\left(\operatorname{logosímbolo}{ }^{10}\right)$, que constituye en sí mismo un género específi co de comunicación social, y el distintivo icónico más reconocible y de mayor tamaño que es la imagen física del candidato (isotipo) junto con otros elementos cohesivos.

La segunda dicotomía es la constituida por mensaje verbal/mensaje no verbal. Queda patente que el eslogan (claim) constituye un mensaje verbal. El lema "ESPERANZA" no sólo es hermoso y positivo - no ataca al contrario- sino que puede ser considerado como una metáfora que supera con creces, desde un punto de vista polisémico, al de la imagen. Yus Ramos (1997:159) afi rma que todo mensaje verbal en cualquier contexto comunicativo llama la atención del destinatario con mayor fuerza que los mensajes no verbales. El rango de referencia de la palabra es enorme porque se emplea el recurso pragmático-retórico del enunciado suspendido o entimema (tener esperanza de algo) para reforzar su contenido. Mediante esta ambigüedad deliberada, se deja en manos de cada receptor la asignación de referente y la desambiguación para la creación de un supuesto no demostrativo (comunicación encubierta) que será distinto en un afroamericano, en un ecologista o en un agricultor, en un desempleado, en un inmigrante, en un antibelicista o en una persona gay. Mediante el proceso de enriquecimiento se dotará al supuesto o implicatura básica (key assumption) de relevancia subjetiva, se convertirá en una implicatura previsible (target assumption) como forma lógica abstracta. Cada individuo hará una adaptación propia del código según su experiencia personal y la interpretación

\footnotetext{
${ }^{10}$ En publicidad se entiende por logosímbolo a la unión de elementos formales, simbólicos y tipográfi cos que sirven de insignia a una empresa representándola, caracterizándola y diferenciándola de su competencia.
} 
que sobrevenga pertenecerá a su particular sistema de valores como meta-representación. Es la metáfora clásica de Pandora, quien tras abrir la caja mostró a la humanidad la esperanza como la única forma de combatir todos los males.

La tercera dicotomía es la establecida entre transmisión de información intencionada/ no intencionada. Entendiendo por la primera el deseo manifi esto de comunicar una información y, por ende, la segunda como la ausencia de éste. La comunicación política siempre tiene intencionalidad. Alegamos anteriormente que el cartel electoral constituía una comunicación dialógica que implica una intencionalidad más inmediata del autor al producir el texto multimodal: buscar los destinatarios. Hemos hablado posteriormente de la pretensión de que cada lector creara una meta-representación personal a partir de la palabra "esperanza" lo que signifi ca que en la mente del receptor ha sido conformado alguno de estos tres elementos: un pensamiento de otro individuo, un enunciado de otro individuo o una representación abstracta. Pero volviendo al emisor, la intención dialógica es sólo el primer paso, coexisten con ella intenciones aparentes -lo que el autor dice-, y subyacentes -aspectos interpretativos que comparten diferentes lectores del mismo texto- Alcanzar la meta-representación tan sólo constituye una intención implicativa, que a nuestro entender es débil (weak assumption) porque responde a una intencionalidad aparente. El propósito más poderoso del mensaje es la persuasión de votar para propiciar un cambio político y social que conlleva la existencia de una intención subyacente a la que se llega por la mayor fuerza de un nuevo supuesto, es decir, mediante implicaturas fuertes (strong assumptions) que crearán la auténtica relevancia. Coincidimos con Trujillo Sáez (2001) en que la comprensión de estos productos híbridos se basa en el concepto de implicaturas fuertes y débiles de la teoría de la Relevancia.

La cuarta dicotomía es la instaurada entre máxima efi cacia comunicativa/mínima efi cacia comunicativa. La máxima efi cacia interpretativa se consigue en dos situaciones de recepción del discurso: a) cuando el destinatario interpreta el mensaje intencionado del emisor en el sentido que éste desea y b) cuando el destinatario accede a la información que se desprende del entorno (social, cultural, físico, etc.) de una forma óptima: se infi ere el mensaje, se enriquece con el conocimiento del mundo y con las creencias.

El proceso de comunicación electoral diseñado en esta campaña no sólo persigue la máxima efi cacia comunicativa sino que tiene, además, un importante componente social: captar un receptor que contribuya practicando el activismo propagandístico y el interaccionismo simbólico se convierte en el colofón intencional subyacente. Un ejemplo palmario de esto lo podemos advertir en las fotografías que incluimos a continuación que suponen una intervención directa en la vida cotidiana.
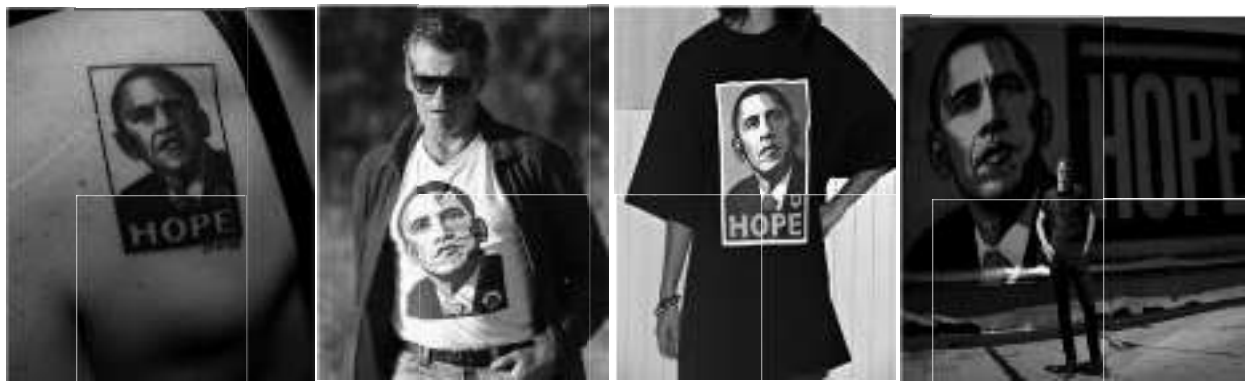
Tampoco podemos perder de vista las posibles reacciones adversas en las que la comunicación ha fracasado porque el destinatario no acepta el mensaje o lo desprecia y las posibles estrategias de ataque y difamación de los adversarios que hay que tener muy en cuenta para saberlas desarticular.

En resumen, nos encontramos ante un acto de comunicación público pero cuya interpretación puede ser privada. Está constituido por un conjunto de componentes simbólicos del candidato de carácter único e irrepetible. Taxonómicamente se corresponden con el supuesto $\mathrm{n}^{\circ} 1$ del modelo escripto-icónico de Yus Ramos: comunicación dialógica, verbal, intencionada y de máxima efi cacia comunicativa.

Por razones claramente comprensibles no podremos tratar in extenso la dimensión retórica del fenómeno publicitario que enlazaría con las competencias paralingüísticas en comunicación y, en consecuencia, con los planteamientos aristotélicos sobre la persuasión basada en el trípode constituido por el "ethos", el "pathos" y el "logos". El "ethos" depende de la personalidad del hablante y ésta se expresa en el póster mediante el uso de elementos diversos: el vestuario y un corte de pelo cuidado ayudan a centrar la atención de los lectores en la expresividad de su rostro y de su mirada. Esta estética casi mística, de fuerte liderazgo persuasivo, refuerza su mensaje. Andrew Sullivan escribió en The Sunday Times" "What has been truly amazing is the preternatural calm and moderation Obama has shown throughout this volatile and emotional campaign”. El segundo soporte lo constituye el "pathos" o la capacidad de situar al receptor en un esquema mental (frame of mind), apelando para ello a las emociones, a la creación de empatía y a la imaginación. Mediante el "pathos" se exterioriza el dinamismo emocional y el valor de la subjetividad como un recurso pragmático. El tercer puntal lo confi gura el "logos" que se basa en las pruebas proporcionadas por las propias palabras del discurso "HOPE” y, más tarde, "CHANGE", "PROGRESS" y otros eslóganes derivados como "CHOPE" (donde el cambio conoce a la esperanza). De forma que se produce lo que en publicidad se conoce como transcontextualización: la imagen ancla no uno de los signifi cados posibles sino también los nuevos lemas que innovan y transforman los contextos convirtiéndolo en un discurso encadenado. En la actualidad la retórica, y especialmente la retórica visual, ha adquirido una nueva dimensión y es considerada como una forma de situar el fenómeno de la expresión humana en formatos híbridos.

Fue R. Barthes (1964) en su Retórica de la imagen ${ }^{12}$ quién planteó que toda imagen es, en principio, polisémica porque contiene una gama de signifi cados siendo, su lectura, múltiple. Como hemos tratado de mostrar con todo lo antedicho, la carga retórica de la imagen puede ser descodifi cada e interpretada mediante los instrumentos analíticos que según dejan entrever Sperber y Wilson puede proveer la Pragmática: la intencionalidad, la indagación inferida y contextual o aquella que añada información a la ya expresada explícitamente para la construcción de nuevas creencias.

\footnotetext{
${ }^{11}$ Lo que resulta verdaderamente asombroso es la extraordinaria calma y moderación mostrada por Obama durante esta volátil y emocional campaña. http://www.timesonline.co.uk/tol/news/world/us and americas/ us elections/article5061437.ece

${ }^{12}$ R. Barthes estableció en 1964 la defi nición teórica de los mecanismos retóricos que actúan en el plano de la connotación de la imagen publicitaria. (RolandBarthes, Retórica de la imagen. Paidós Comunicación. Barcelona, 1994)
} 

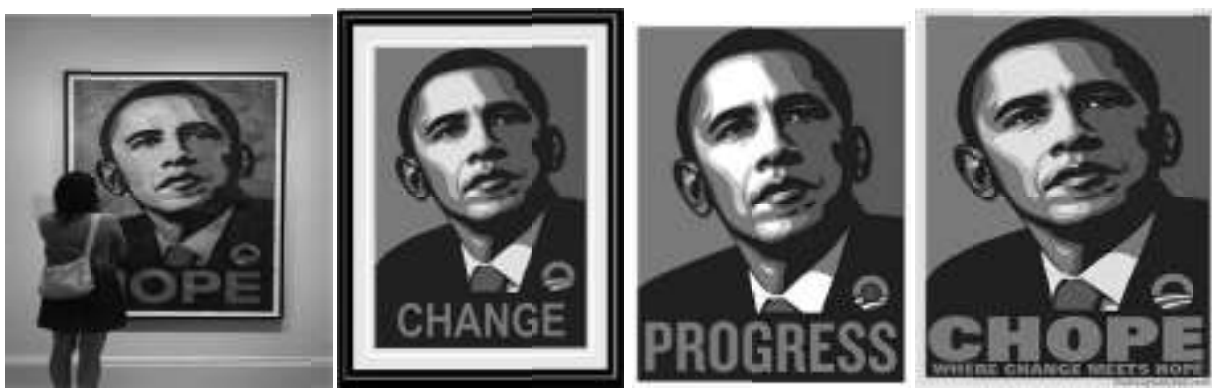

MENSAJE INTERESADO Y LENGUAJE HOSTIL EN POLÍTICA

Cuando un partido es poderoso cuenta con los medios necesarios para entrenar a los candidatos en el uso del lenguaje y lo hace con una doble fi nalidad: la de ensalzar los propios logros y la de atacar al contrario. En 1994 el Partido Republicano a través del GOPAC ${ }^{13}$ creó un polémico memorándum titulado Language: A Key Mechanism of Control que contenía unas listas de palabras con connotaciones positivas y negativas que debían ser usadas para elogiar a los miembros e ideas del partido y para describir mediante connotaciones negativas a los oponentes políticos y a sus planteamientos. Más adelante veremos cómo se aplican estos conceptos a las variantes críticas del cartel que han ido apareciendo en Internet. Los emisores de estos mensajes caricaturescos, cargados de intención, se basan en un determinado contexto cuando tratan de causar un efecto determinado en el entorno cognitivo ${ }^{14}$ del receptor-diana de su emisión y de esta forma establecer una manifestación mutua (mutual manifestness) apelando, en muchas de ellas, a la creación de predisposiciones duraderas de carácter emocional que resultarían de la formación de un conjunto intrincado de supuestos que es el equivalente de un proceso cognitivo complejo.

Con el fi $\mathrm{n}$ de producir un primer acercamiento a lo argumentado y antes de adentrarnos en un intento clasifi catorio o taxonomizador de los carteles paródicos y contrapublicitarios, echemos un vistazo apresurado a estos ejemplos.

\footnotetext{
${ }^{13}$ GOPAC (Grand Old Party Action Committee) La primera organización para el entrenamiento de los candidatos republicanos. Ver en [ http://web.utk.edu/ glenn/GopacMemo.html ]

${ }^{14} \mathrm{El}$ conjunto de ideas manifi estas que consideramos verdaderas o probablemente verdaderas en un momento dado constituye nuestro entorno cognitivo (Sperber y Wilson, 1986:39).
} 


\section{SPEAKING OF RACESSIONS...}
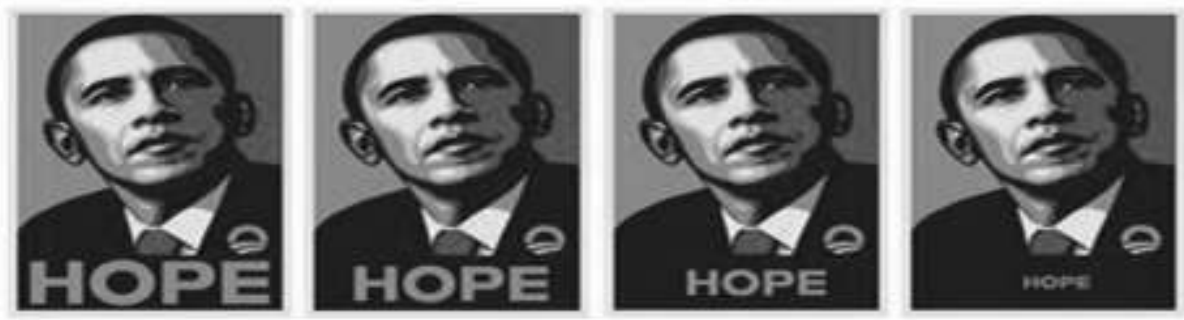

Observemos en esta muestra ${ }^{15}$ cómo la repetición del modelo establece una narrativa en la que los espacios en blanco entre los carteles, de la misma manera que la calle (o gutter en los cómics), instauran una transición o secuenciación gradual producida con y desde las coordenadas del tiempo. Se trata de una competencia comunicativa de carácter cronético $^{16}$. La tipografía es la que juega aquí un papel importante en la comunicación del mensaje. La progresiva disminución del tamaño de los tipos transmite de manera efectiva que la esperanza se desvanece: "Hope is diminishing across the nation, Mr. Obama". Desde el punto de vista de la Teoría de la Relevancia el enunciado más literal, su contenido explícito (explicatures) no tiene necesariamente que ser el más relevante. El letrero resumen (summary caption) nos aclara que estamos hablando de la Crisis. La atención se centra en los procedimientos de enriquecimiento pragmático emplazados en la tipografía y en las calles (gutters) que son las que nos conducen a la inferencia en un visible ejemplo de transcontextualización.

Otros casos pueden avalar lo expuesto como cuando se produce una disonancia isotópica en la que lo icónico y lo verbal están diciendo explícitamente lo contrario. Un comunicador nos muestra el mismo cartel electoral con una modifi cación en la imagen: Obama aparece vestido con un traje militar de campaña y empuñando un arma. Su logotipo ha sido sustituido por "Afganistán”. La lectura literal de la imagen nos habla de guerra, el eslogan nos habla de esperanza; imagen y texto llevan caminos diferentes, está claro que la relevancia provendrá de la comprensión inferencial que cada individuo haga en su sistema central de estos dos inputs discordantes. Si el contexto de lectura es antibelicista los supuestos a procesar serán muy críticos (implicated premises) y conducirían a la afi rmación (implicated conclusions): la guerra es un crimen, ¡detenga esa guerra presidente Obama! que canalizarían a plantearse preguntas como las del fi lm Rethink Afghanistan dirigido por Robert Greenwald. Bien diferentes podrían ser los supuestos de un grupo militarista donde tal vez lo que quisiera expresarse fuera la esperanza en la victoria. Existe una falta de cohesión entre ambos campos isotópicos, no olvidemos que mediante la

\footnotetext{
${ }^{15}$ Realizada por el dibujante Steve Breen para "The San Diego Union-Tribune".

${ }^{16}$ Hemos utilizado la terminología de E. Jailler Castrillón en su artículo Internet y la formación de competencias a partir del uso de la prensa on-line. http://www.acorn- edecom.org/papers/acornredecom2009jaillier.pdf . Según la autora competencias cronéticas son las que se relacionan con la oportunidad y pertinencia temporal de los mensajes.
} 
isotopía se confi guran campos de signifi cación debido a la coherencia de los términos que aparecen en el texto.

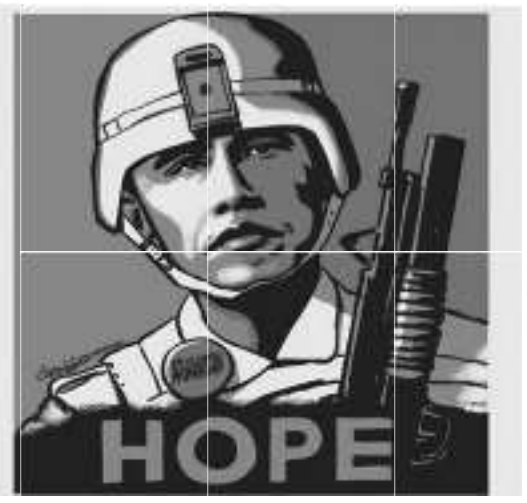

Por otra parte, en cartelística política electoral, es frecuente el fenómeno que podríamos encuadrar dentro de una pragmática de la comunicación con cierta carga "patológica", de condición dialógica puesto que se produce entre un comunicador y unos destinatarios, multimodal por su naturaleza icónico-verbal, de carácter indirecto porque se engendra mediante la alteración intencionada por cualquier procedimiento del mensaje original y diferida en el tiempo ya que puede desencadenarse en un lapso temporal de distinta duración. Es el caso tan habitual en campaña que se genera cuando algunos de los receptores no coincidentes con la intencionalidad comunicacional de un reclamo político exteriorizan su disconformidad, criticando o parodiando estos mensajes y para tal fi $\mathrm{n}$ insertan en ellos elementos extraños como la adición de un bigote, el tachado de una parte del eslogan, como podemos observar en el chiste de Adam Zyglis ${ }^{17}$, los alteran completamente o efectúan en ellos profundas reformas valiéndose de variados instrumentos y procesos que podemos encontrar por miles en la Red.

Así pues, cuando una persona que no pertenece a esa comunidad, desde una aparente neutralidad, paseando por la calle o como en nuestro caso navegando por la Web, observa, como hallazgo casual (serendipity) o mediante la búsqueda deliberada de imágenes, cada una de estas manifestaciones discrepantes puede llegar a percibir primero e inferir, más tarde, ciertas interacciones sociales que pueden ser objeto de interpretación. El intérprete podrá recurrir a su almacén de datos de la memoria enciclopédica y a su conocimiento del mundo o a la documentación deliberada, si desea extraer información más precisa. Lo que

\footnotetext{
${ }^{17}$ Adam Zyglis es un dibujante de viñetas editoriales (editorial cartoons) que trabaja, entre otros medios, para "The Buffalo News" periódico de la segunda ciudad más poblada del Estado de Nueva York. Nótese cómo el humor se centra en los elementos simbólicos de la persona que ha realizado las tachaduras con el espray: su rostro es el de un auténtico ogro que va vestido con la indumentaria del Tío Sam -el símbolo de EEUU -que ha perdido su levita y muestra su desgarrada camisa (¿por culpa de los impuestos?). Las bolsas de té que penden del sombrero lo identifi can como un teabagger pero para disipar dudas, si las hubiera, muestra sobre su pecho el distintivo (badge) del Tea Party. Finalmente los símbolos metafóricos clavados en el sombrero constituidos por la bandera del Partido Republicano (GOP: Grand Old Party) indicando mediante una señal de tráfi co que el país es de los republicanos y, fi nalmente, la enseña de la cadena de televisión 'Fox News' contextualizan meridianamente los sectores desde donde proviene la discrepancia. Las metáforas visuales aparecen concebidas como fenómenos mentales o mecanismos cognitivos.
} 
sí parece claro es que apreciando esa rica pluralidad de mensajes que no pertenecen a un discurso homogéneo sino a una variedad amplia de situaciones y registros le ayudarán a incrementar su conocimiento cultural de esa comunidad porque todas y cada una de esas señales pueden llegar a refl ejar valiosos componentes del patrimonio político-cultural de una nación.

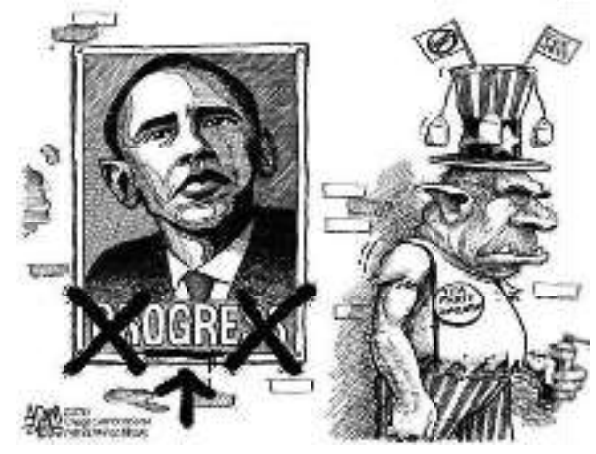

Sostenemos que una de las posibles aplicaciones de la teoría de la relevancia es la explicación de los fenómenos paródicos y de humor gráfi co-satírico en política ${ }^{18}$. Este tipo de humor constituye una herramienta de uso social que facilita la actualidad informativa y establece pautas culturales, formulando así una crítica de conductas. La comunicación comprendida de este modo funciona como un sistema (un proceso) en el que los interlocutores participan mostrando con sus mensajes un comportamiento social que intuye el intérprete pero que ha sido fruto de conductas individuales diversas y distanciadas cronológicamente. Con el fi n de ejemplifi car este proceso incluimos a continuación este chiste editorial del dibujante y artista multimedia Patrick Blower.

\footnotetext{
${ }^{18} \mathrm{El}$ chiste editorial es un producto que, desafortunadamente, ha dejado de tener la importancia que poseía en el pasado cuando constituía una parte importante de la identidad de cualquier periódico. Se trata de una tradición tan antigua como el propio medio confi gurando una pieza muy apreciable de la cultura estadounidense.
} 


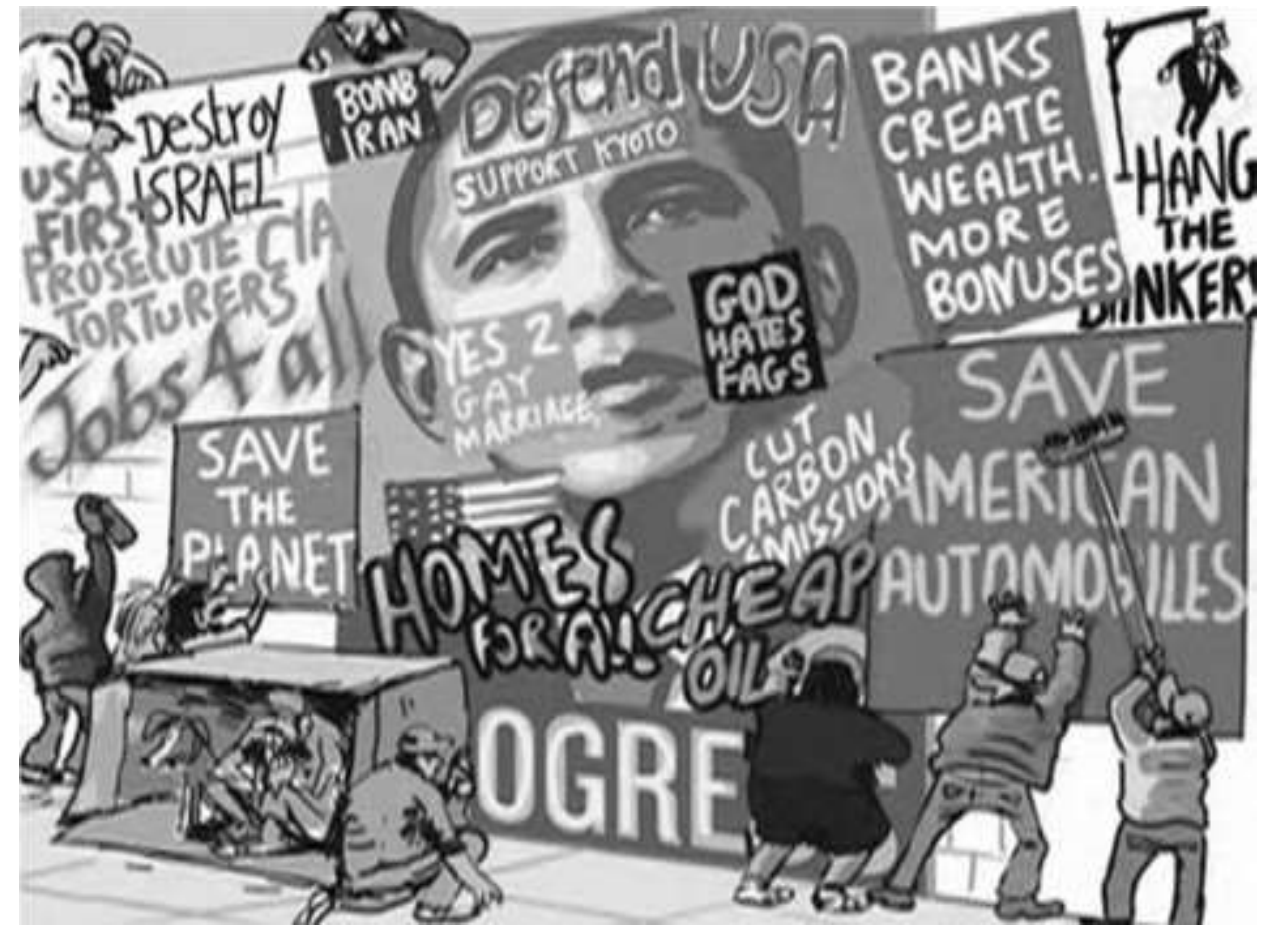

El muro se encontraba originariamente ocupado por el cartel de Barack Obama con el eslogan "PROGRESS". Sin embargo, este póster electoral de carácter persuasivo va recibiendo respuestas gráfi co-verbales provenientes de una variedad compleja de receptores activos, algunos de los cuales se exhiben en el dibujo. Estas réplicas propician la creación de una suerte de discurso circular de carácter heterogéneo, en el que aparecen gran variedad de registros y diferentes actitudes ideológicas. La posición de algunos personajes como el hombre sin techo (homeless) y el chico que usa el espray para pedir gasolina más barata cubren parte del lema de manera que Obama aparece como un ogro (ogre). La comunicación así comprendida trabaja como un proceso en el que los interlocutores participan activamente. Sus actitudes y sus comportamientos como miembros de una cultura establecen un estilo de comunicación en la que, si se nos permite el símil, algunos de los destinatarios actúan como los músicos que forman parte de una orquesta. Pero como afi rma Yves Winkin (1987:6), “en esta orquesta cultural no hay director ni partitura. Cada uno toca poniéndose de acuerdo con el otro. Sólo un observador exterior, es decir, un investigador de la comunicación que haga el papel de intérprete puede elaborar progresivamente una partitura escrita, que sin duda se revelará altamente compleja". No vamos a detenernos a contextualizarlas pero sí que podemos constatar que las replicas al mensaje original contenidas en este texto enmarañado pueden organizarse 
según los temas tratados ${ }^{19}$ : económicos, sociales, ecológicos y los referentes a la política exterior americana. Algunas de estas visiones son notoriamente contrapuestas e invitan sin timidez al debate.

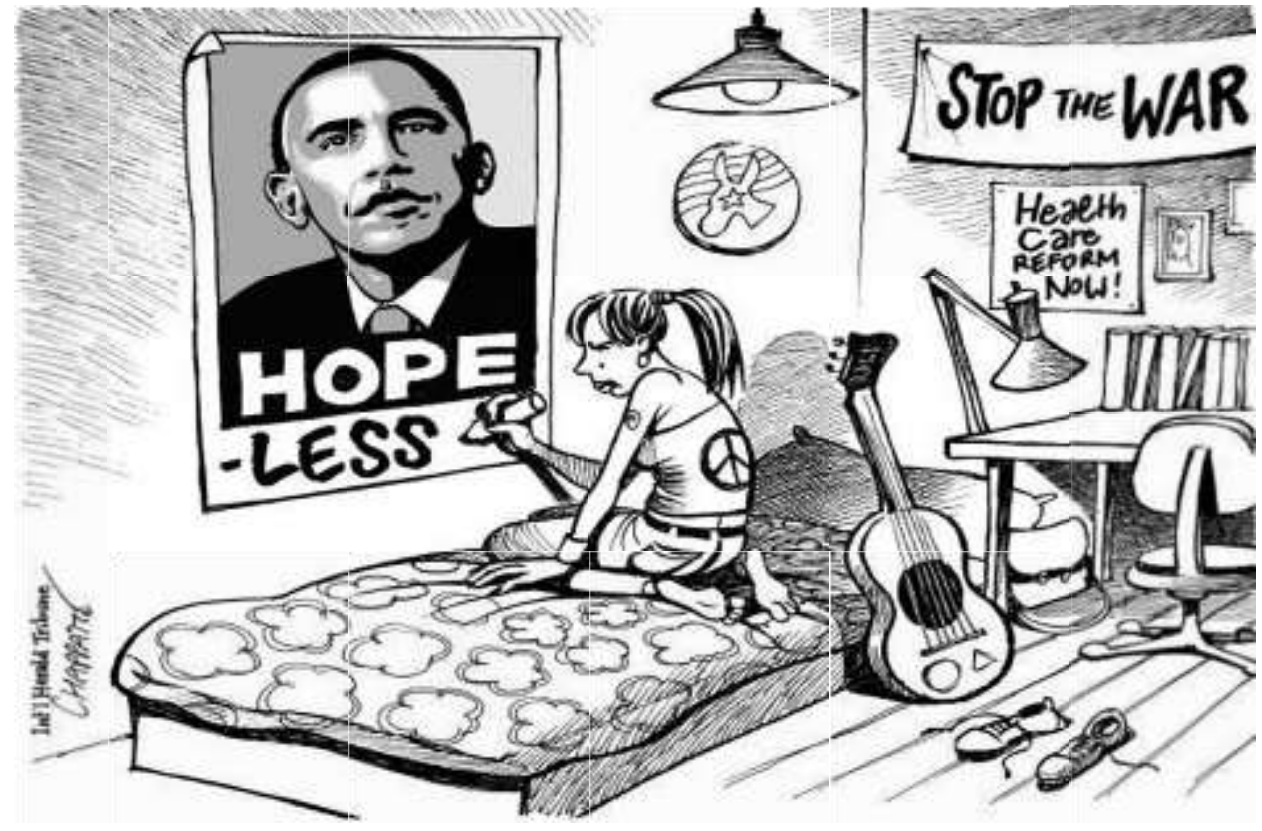

Esta viñeta gráfi ca de Patrick Chappatte ${ }^{20}$ puede ayudarnos a comprender cómo las exageradas expectativas de los sectores reformistas se han visto defraudadas (obsérvense los usos metafóricos del símbolo de la cabeza del burro que es el logo del partido demócrata americano y del emblema de la paz usado en los años 60 por la cultura y movimiento hippie y ahora por los antibelicistas). Estos grupos que valoraron como una revolución en la política de Estados Unidos la elección de Barack Obama ven cómo sus anhelos comienzan a transformarse por la difi cultad real de ser llevados a cabo produciéndoles desconcierto, decepción y desesperanza. Yus Ramos sostiene que la inmovilidad espacio-temporal de los productos verbo-icónicos facilita la labor investigadora. Nuestra actividad como intérpretes es una actividad pragmática que nos impone actividades de contextualización del discurso visual (visual aspects of the cartoon) $\mathrm{y}$ del discurso textual (verbal aspects of the cartoon) y nos obliga a identifi car y analizar las razones del creador del discurso de fi cción (overall effect of the cartoon). El humor

\footnotetext{
${ }^{19}$ Económicos: Los bancos crean riqueza más bonifi caciones/ Cuelga a los banqueros/ Socorre a la industria americana del automóvil. Sociales: Trabajo para todos/Gasolina más barata /Casas para todos/ Sí al matrimonio homosexual/Dios odia a los maricas. Ecológicos: Respalda Kioto/Salva el planeta/Reduce las emisiones de carbono. Política exterior: Defi ende USA /Bombardea Irán /USA es lo primero/ Destruye Israel/Persigue a los torturadores de la CIA.

${ }^{20}$ Patrick Chappatte es un humorista gráfi co libanés y suizo que trabaja para diferentes medios entre los que podemos señalar The International Herald Tribune. Podemos consultar el chiste en http://www.fvsports.com/ forum/showthread.php?125082-Obama-is-fi nished......one-and-done......history .
} 
gráfi co crea una situación comunicativa que nos hace presuponer que los personajes de esta trama se comportan de forma análoga a personas reales y por consiguiente pueden hacer uso de una amplia gama de estrategias conversacionales sobre la base de unos conocimientos compartidos entre una comunidad de hablantes que es lo que hace posible la comunicación..

\section{APROXIMACIÓN A UNA CATEGORIZACIÓN}

Para este fi n, hemos seleccionado un pequeño corpus de las réplicas paródicas del cartel electoral de Obama provenientes en su totalidad de Internet. Muchos de ellos pueden ser considerados como carteles desmotivadores (demotivational posters), otros como política furiosa (raging politic) e incluso como retórica tóxica (venemous political rhetoric). Hemos situado la selección en una sincronía que abarca desde su etapa como senador por el estado de Illinois hasta el momento actual. Esta línea cronológica se subdividiría, sólo a efectos informativos, en varios tramos: la etapa electoral, la lucha por la presidencia, la transición presidencial de Barack Obama, los primeros cien días, el periodo posterior hasta la aparición del Tea Party, las elecciones de mitad de mandato (mid-term elections) y de éstas a la campaña del 2012.

La evolución de los discursos y de las interacciones de carácter epidemiológico y viral que se dan en la actualidad en la Red ha sido tan espectacular que Yus Ramos, en su Ciberpragmática (2001), la considera en sí misma como un amplio campo de estudio en el que convergen diferentes posibilidades de investigación pragmática. La gran contribución de los estudios bajo el marco investigador de la pragmática es precisamente la certeza de que es imposible analizar el lenguaje si lo separamos del contexto en que éste surge y es interpretado.

Nuestra posición de partida es distinta, nosotros como lectores secundarios no oriundos, hemos intentado suplir mediante la documentación nuestras carencias. Hemos ido creando nuestros supuestos no demostrativos con una carga emocional mucho más distante. Nos hemos basado en la hipótesis de que pueda existir una actitud intencional de naturaleza ecoica y supuestamente conversacional entre el cartel original y los paródicos en que el grado de crispación política va aumentando de manera progresiva como si fuera posible romper el principio de unidireccionalidad de la publicidad y lo pudiéramos dotar de una cierta carga de reciprocidad. Apoyándonos en ella hemos establecido una serie de categorías. Por razones obvias de extensión no podremos tratarlos más que de manera superfi cial (únicamente como apoyatura del contenido de cada cartel) y sin perder de vista, como ya expresamos previamente, su condición de conjeturas razonables.

Nuestra propuesta de aproximación categorizadora está basada en un chiste editorial de Mike Luckovich ${ }^{21}$ sobre los grados del discurso y la violencia sobrevenida en Tucson (Arizona). Está constituida por ocho diferentes jerarquías, a saber: al grado uno lo hemos denominado bromas irritantes (happy and irritating talk), al grado 2: conversación animada (warm conversation), al grado 3: debate amistoso (friendly debate), al grado 4:

\footnotetext{
${ }^{21}$ Cartoonist Mike Luckovich's take on angry rhetoric. Ver en http://www.ajc.com/opinion/todaysmikeluckovich-cartoon-802319.html
} 
discusión vehemente (spirited discusión), al grado 5: discurso airado (angry discourse), al grado 6: diatriba no exenta de odio (hateful speech) y al grado 7: retórica violenta (violent rhetoric).

A) Grado 1: Bromas irritantes
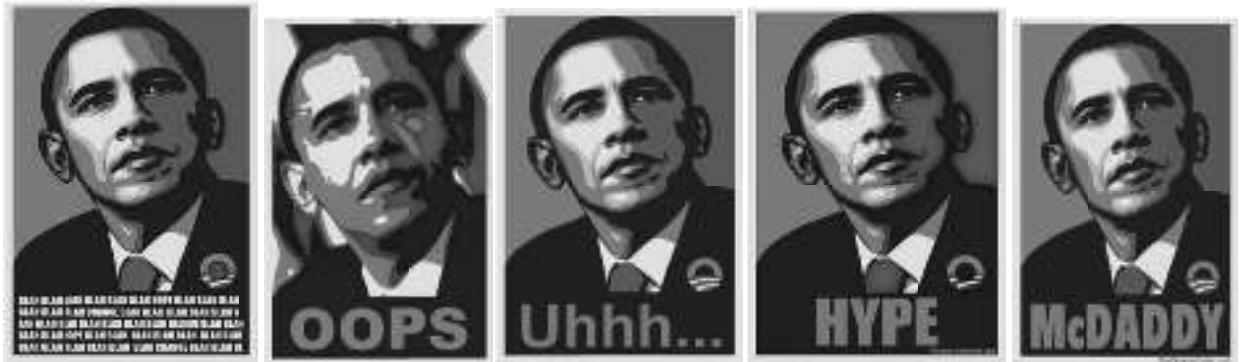

Se tratan asuntos superfi ciales cuya fi nalidad es bromear (happy talk) o producir una leve pero incisiva crítica para causar irritación en el receptor por determinados comportamientos del personaje (irritating talk). Se utilizan modifi caciones en el elemento verbal o lema como la interjección "Blah” repetida durante cinco líneas, dependiendo del momento cronológico elegido, puede contextualizarse como que el discurso electoral de Obama sólo son palabras huecas, sin signifi cación alguna o con la intención de recriminarle un cúmulo de promesas electorales incumplidas si lo enmarcamos en otro ciclo temporal caracterizado por la fusión del logo con el sello presidencial de su solapa. Las interjecciones coloquiales son palabras que, desde un punto de vista pragmático, están dotadas de gran expresividad y poseen también un considerable poder alegórico, dada su capacidad de evocar imágenes y suscitar sensaciones en el receptor. Tal es el caso de "OOPS" exclamación que se produce cuando se comete un error o coloquialmente se mete la pata-Obama es una máquina de meter la pata-o la invitación al lector para que obtenga una inferencia que se desprende cuando se dota de contenido a un alargamiento fónico como "Uhhh..." para expresar que el orador no sabe qué decir porque le ha fallado el teleprompter. Para restar importancia a la impresionante fuerza del fenómeno Obama se utiliza la palabra "HYPE" (hipérbole) que equivale a considerarlo como un "boom" propagandístico. Obama es sólo una moda pasajera. Uno de los críticos de Obama es el Pastor James David Manning de la ATLAH World Missionary Church in Harlem. Una intervención suya puede ser el contexto que nos ayude a situar el lema "McDADDY" que en el argot urbano se asemeja a macarra y chulo. Este reverendo en un momento acalorado de un sermón dice: Obama chulea a las mujeres blancas y a las negras "Obama pimps White women and Black women", Obama es un proxeneta patilargo "Obama is a longlegged McDaddy” en relación a su apoyo a la conocida canción de Obama girl22: “I Got a

\footnotetext{
22 "I Got a Crush... on Obama" se trata de un video de publicidad viral que apareció en Internet, concretamente en YouTube en Junio del 2007. Una mujer blanca le expresaba cantando su amor y su deseo al senador Barack Obama y manifestaba que él era el mejor candidato. Ver en http://www.youtube.com/watch?v=dyjXt1zSXHU ${ }^{23}$ Se trata de un trabajo del dibujante Nate Beeler titulado: HOPE. NOPE. Obama agenda divides nation. http:// obamaforwards.com/default,month,2010-01.aspx
} 
Crush... on Obama" (estoy chifl ada por Obama). En otro momento pregona que una de las más conocidas seguidoras de Obama, Oprah Winfrey, la celebridad televisiva, es una prostituta babilónica (Babylonian whore). B) Grado 2: Conversación animada
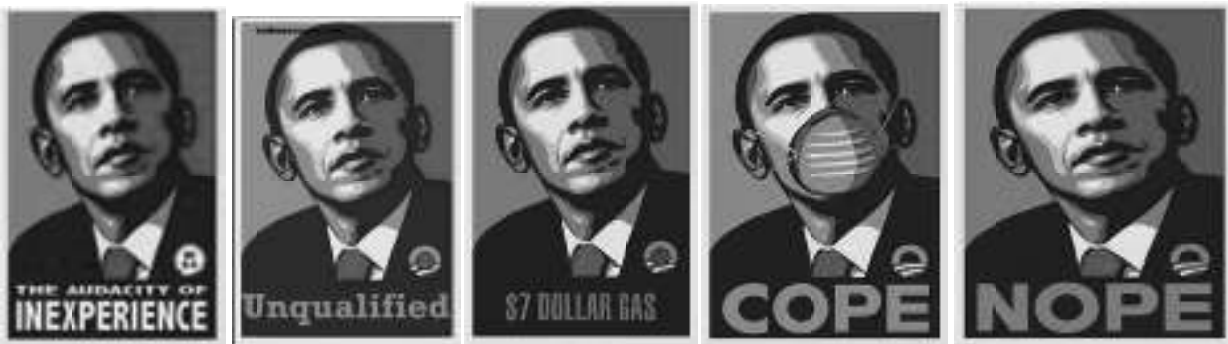

Los contenidos seleccionados poseen intencionalidad crítica y son propios de una conversación animada sobre temas de política (warm conversation). Es el caso de alguien que ha leído el libro de Obama The audacity of Hope y lo usa para modifi car el lema del cartel por The audacity of inexperience para enfatizar que el candidato carece de experiencia de gobierno. Un argumento ampliamente explotado por el equipo de McCain durante la campaña electoral fue considerarlo como un principiante en las artes de la gobernación de ahí que "unqualifi ed" sirva para sopesar que se trata de una persona sin pedigrí político y, por tanto, incapaz de presidir un país tan importante o acusarle, siendo ya presidente, de que su gobierno no ha sabido manejar con fi rmeza los temas energéticos y como consecuencia la gasolina subió de precio hasta alcanzar los 7 dólares el galón lo que está llevando a la economía al borde del colapso. El póster de Obama "COPE", entimema o enunciado suspendido por (to cope with something: sobrellevar algún problema) coloca una máscara sobre su boca, como su única acción efectiva, para hacer frente a los efectos de la fi ebre porcina producida por el virus (H1N1) y para refl ejar el pánico social existente por la aparición de esta enfermedad. El lema "NOPE", no hay esperanza, no votes a Obama es un claro ejemplo de publicidad política disuasoria. En su etapa de presidente una viñeta editorial ${ }^{23}$ muestra cómo se ha desplomado la barra horizontal de la "H" de "hope" formando la letra "N" y transformando, por tanto, la palabra hope en nope. La leyenda resumen (summary caption) dice: "La presidencia de Obama: Año Uno".

\section{C) Grado 3: Debate amistoso}
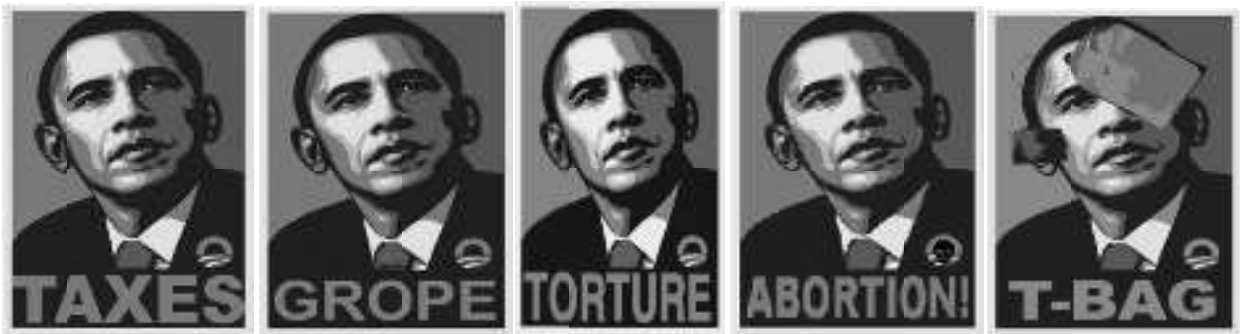

Los asuntos seleccionados podrían ser tratados en un debate serio pero sin perder las formas (friendly debate). Se polemiza sobre temas de gobierno de mayor seriedad como 
los impuestos, la vigilancia de aeropuertos, la tortura, el aborto o el papel de Tea Party. Si situamos el cartel "TAXES" y lo ubicamos en las cercanías de las "midterm elections" nos estaría mostrando la angustia de las clases medias de rentas elevadas por la subida de impuestos, en pleno período de recesión, que les han supuesto las reformas de Obama como evidencian estos lemas: estamos en guerra contra más impuestos "On war path against more taxes", Obama, no soy tu cajero automático “Obama, I am not your ATM"33”. Lo que realmente están reclamando es la desaparición de servicios esenciales como, por ejemplo, la sanidad, las pensiones o la educación pública. El verbo "GROPE" que coloquialmente signifi ca manosear o meter mano cobra vigor en el contexto del aumento de los cacheos, chequeos con rayos $\mathrm{X}$ y otras medidas de seguridad en los aeropuertos llevados a cabo por la TSA (Transporting Security Administration). "TORTURE" puede contextualizarse como una paradoja legal: en su tercer día como presidente, Barack Obama fi rmó órdenes ejecutivas para prohibir la tortura, la clausura defi nitiva del centro de detención de Guantánamo, el fi n de los centros de detención clandestinos de la Cía. y un procedimiento de reevaluación de los encarcelados bajo sospecha de terrorismo, lo que rebatía algunas de las medidas y políticas más criticadas a escala mundial promovidas por el gobierno de George W. Bush. Los grupos más conservadores no están de acuerdo con estas medidas porque los torturadores de la anterior administración podrían ser ahora denunciados y acusados originando el contrasentido ${ }^{24}$ legal al que hemos hecho referencia. Situado en el contexto de las elecciones de mitad de mandato (midterm elections) nos encontramos "TORTURE” en un pasquín como un acróstico ${ }^{25}$. En el cartel "ABORTION!" las asociaciones pro-vida americanas están realmente indignadas con las declaraciones de Obama señalando que está de acuerdo con que se restrinjan los abortos tardíos, pero abogando por una cláusula que permita una excepción en caso de riesgo de muerte de la madre. Esa es la razón por la que colocan un cráneo negro sobre su logo como una asociación visual con la palabra infanticida. "T-BAG" -bolsa de té- sobre el rostro de Obama hace referencia al Tea Party, nombre que proviene de una rebelión de fi nales del siglo XVIII acaecida en la ciudad de Boston cuyo objetivo era no pagar impuestos si no podían escoger a sus representantes. Este acontecimiento histórico ha inspirado siempre la propaganda sobre protestas fi scales. Desde su nacimiento en 2009, el Tea Party se ha erigido en un peligroso enemigo de Obama. Sus miembros "teabaggers" deben fi rmar un manifi esto denominado "contrato con EE.UU.", en el que se encuadran algunos de los "leitmotiv" de la corriente conservadora: (1) Proteger la Constitución. (2) Exigir un presupuesto equilibrado (responsabilidad fi scal). (3) Recortar el gobierno (que debería

\footnotetext{
${ }^{23}$ Cajero automático (automated teller machine) conocido por sus siglas (ATM).

${ }^{24}$ Naomi Wolf, conocida feminista de ideología progresista afi rmó en la entrevista del 30 de Marzo de 2010 con el sitio web Alternet: "Bush legalized torture, but Obama is legalizing impunity. He promised to roll stuff back, but he is institutionalizing these things forever. It is terrifying and the left doesn't seem to recognize it". http://www.alternet.org/story/146184/?page=entire

${ }^{25}$ En la parte superior derecha de este cartel puede verse a un hombre que piensa: Huh! I thought Obama was against TORTURE! El titular (headline) dice: One disaster after another. A continuación aparecen los siete versos que confi guran el acróstico TORTURE, a saber: Tax increases during a recession/ Overhaul Healthcare to Gov’t Run/ Raise Energy Cost thru Cap \& Trade/ Treat terrorists as US citizens/ Undermine the US Constitution/ Redistribute your wealth/ Economics: Destroy Capitalism. Finalizando con el lema: "We need change: Vote in 2010".
} 
estar limitado constitucionalmente) y evitar el bipartidismo. (4) Derogar o reemplazar el seguro gubernamental de enfermedades (abogan por un mercado libre). (5) En relación con la inmigración existe un cierto contagio del fenómeno xenófobo de Arizona. Se trata en suma de un movimiento de base que aglutina a gran número de mujeres y hombres blancos de clase media muy conservadora aterrorizados por los impuestos y golpeados por la crisis económica. La llegada de un negro a la Casa Blanca ha sido algo muy negativo y por ello lo consideran como un marxista, un nazi o un racista contra los blancos -temas que aparecerán en diferentes apartados de nuestra gradación-. Entre sus eslóganes afi rman: soy estadounidense no antiestadounidense, ¡despertad! "I'm American not unamerican. People wake up!" o reivindican ser un puñado de estadounidenses que quieren recuperar su país:

"What we are is a bunch of Americans who want our country back".

\section{D) Grado 4: Discusión vehemente}
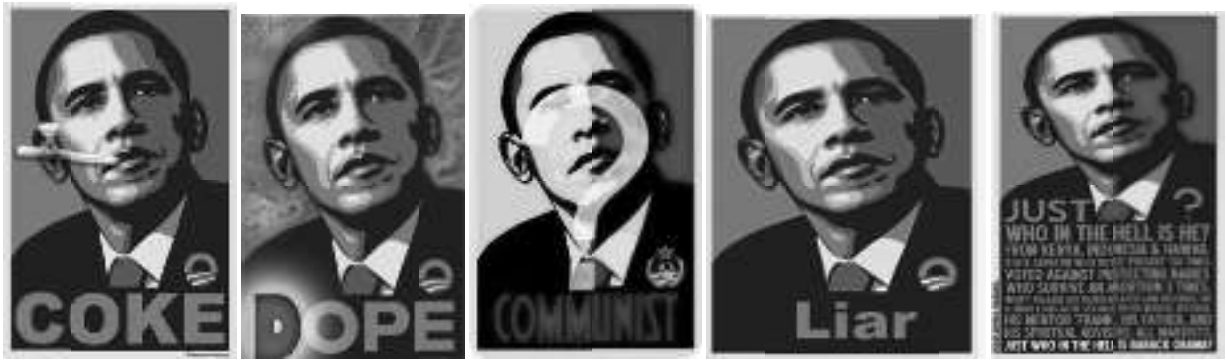

Sarcasmos y otros contenidos seleccionados de carácter muy crítico relacionados con la vida personal, propios de una discusión vehemente (spirited discussion). El hecho de que Obama en el libro autobiográfi co titulado Dreams of My Father reconociera con cierto grado de honestidad y de ingenuidad haber consumido en su juventud cocaína y hachís permite a sus rivales usar esta información con mordacidad en los carteles "COKE", expresión familiar por cocaína y "DOPE" que, en argot, tiene el signifi cado de hachís, razón por la que se introduce el color verde de "hierba" y se sustituye la letra "H" por una "D”. ¡Cuidado, un drogadicto quiere gobernarnos! El póster "COMMUNIST” ¿es Barack Obama un comunista? La interrogación retórica es un recurso pragmático de gran efecto porque no espera una respuesta verbal sino algún tipo de reacción del interlocutor. El contexto de la pregunta está basado en las revelaciones realizadas en el referido libro para advertir del peligro de la infl uencia del mentor de Obama durante sus años de escuela secundaria, Frank Marshall Davis, considerado comunista así como del temprano contacto del candidato con amistades y organizaciones radicales. Nótese cómo el logo de Obama se ha fundido, por asociación, con el escudo de la URSS. En "LIAR" se deja entrever que Obama miente sobre sus orígenes, sobre el cambio climático, sobre la reforma del sistema sanitario. Obama es un mentiroso compulsivo. En el último ejemplo gráfi co-verbal que aportamos el contexto estaría relacionado con Jake Tapper ${ }^{26}$, corresponsal de ABC News,

\footnotetext{
${ }^{26}$ Sustituir un lema por un texto tan complejo tiene la fi nalidad de facilitar a los antagonistas detalles que no tienen cabida en las parcas palabras de un eslogan y requiere un mayor grado de cooperación cognitiva porque
} 
que en una crónica se refi ere a él como Barack Hussein Obama y pregunta: "Just who in the hell is Barack Obama? And why, in these dangerous times, should he be entrusted with the most powerful job on Earth?" Se ha sustituido el logo por una incógnita retórica y la palabra "Hope" ha sido reemplazada por todo un ideario político en su contra repleto de implicaturas que suponemos relacionadas con un entorno cognitivo compartido por los lectores: "Just-? Who in the hell is he? From Kenia, Indonesia \& Hawaii. State Senator who voted "present" 130 times $^{27}$.Voted against protecting babies who survive an abortion 3 times $^{28}$.Won't release his Rezko-related ${ }^{29}$ law records, his Illinois legislative records or his medical records. His mentor "Frank", his father, and spiritual advisers: all Marxists. Just who in the hell is Barack Obama?. La repetición, al principio y al fi nal, de la pregunta ¿quién diablos es Obama? Es un recurso pragmático-expresivo intenso porque activa la responsabilidad del receptor en encontrar su propia respuesta mediante la activación de implicaturas débiles.

Obsérvese, como comentario adicional, que la utilización en el eslogan de este original 'giro' en la expresión ya normalizada, 'who the hell is.. .' debe pretender alguna implicatura más, por débil que sea, dirigida a ciertos lectores religiosos extremistas que tenderán a asimilarla a la antigua y, en este sentido, se aproximaría más a un discurso airado, limítrofe con la retórica violenta. La novedosa expresión 'who in the hell is OBAMA' resulta próxima o semejante a aquella del poema 'who in the hell is Tom Jones' de Charles Bukowski (poeta americano que, como Allan Ginsberg, Gregory Corso o Farlinguetti fueron considerados 'off-off', de la generación beat y creadores contestatarios al margen de lo comercial). Por consiguiente, la intencionalidad subyacente apunta o alude al candidato a presidente de un modo ofensivo porque, a nuestro juicio, encierra una radical discriminación por las creencias religiosas de las que hace gala el Tea Party: se le envía a los infi ernos. Esa es la lectura de la preposición IN en la expresión idiomática 'who the hell..' (quién demonios es...) donde 'hell' y 'demonio' se vacían de sentido al hacerse idiomática; pero recobra de nuevo su sentido pleno como unidad léxica al dar ese giro inusitado introduciendo la preposición IN: así, el enunciado 'who in the hell is' tiene la clara implicatura -más o menos fuerte- de que 'hell' es el lugar condenatorio en el ámbito religioso donde se halla el candidato indeseado. El juego de palabras, a pesar de la transgresión gramatical del código lingüístico: una frase cuyo primer elemento es 'who' no admite una frase preposicional a continuación 'in the hell' a no ser, que al violentar la

\footnotetext{
se trata de activar un gran número de implicaciones débiles en el receptor dado que no se facilitan las claves para el acceso rápido a la intención. Esta desaceleración del proceso comunicativo exige que el receptor invierta un mayor tiempo en la comprensión del mensaje. Se cumple el siguiente principio: la creencia o credibilidad necesaria del receptor en el emisor a la hora de comunicarnos no procede de la cooperación social sino de la cooperación a nivel cognitivo. From the January 16 edition of ABC's Nightline: http://mediamatters.org/ $\underline{\text { research/200701180002 }}$

${ }^{27}$ Crítica que fue usada también por su compañera de partido Hillary Clinton. Votar "present” (presente) signifi ca no votar ni a favor ni en contra de una propuesta o ley. Equivale a la abstención.

${ }^{28}$ Siendo senador por Illinois votó 3 veces en contra de "The Born Alive Infants Protection Act” según la derecha conservadora, las intenciones de esta ley eran garantizar el cuidado médico para los bebés que sobrevivían los abortos. Votar en contra era permitir que murieran sin atención.

${ }^{29}$ Rezko es un constructor que fue condenado por fraude y soborno. El hecho de ser un importante donante para la campaña de Obama permite insinuar entre ambos una relación corrupta.
} 
norma, queramos dar un sentido distinto, pues la no gramaticalidad del código no impide la comunicación. Es este un fenómeno que se da con relativa frecuencia en el habla cotidiana y, como en este caso, en la publicidad. E) Grado 5: Discurso airado
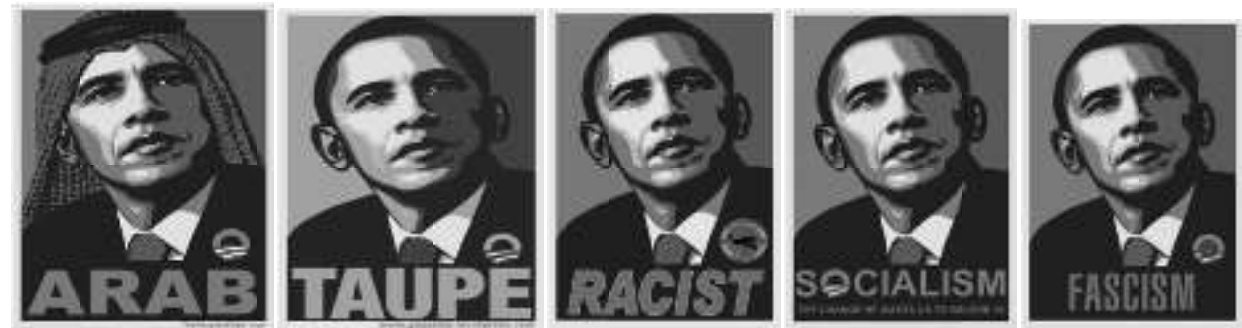

Se examinan temas propios de un discurso airado (angry discourse) o se utilizan argumentos demagógicos (intemperate rabble-rousing). Estos asuntos están relacionados con la raza y con las creencias. Suponen acusaciones formales y una extralimitación verbal (verbal abuse). Se dota a cada uno de ellos de una intencionalidad de hostigamiento mediante la demonización, creando opinión en contra o intoxicando.

Desde un plano puramente visual-descriptivo se está haciendo uso publicitario de determinados estereotipos: árabe, yihadista, terrorista como una estrategia cognitiva efectiva. Se ha criticado a Obama durante su campaña de no ser tan negro como debiera de manera que es presentado como mulato americano "TAUPE", un mestizo nacido de una mujer blanca estadounidense y de un hombre negro originario de Kenia lo que no deja de tener connotaciones raciales negativas. En el cartel "RACIST" se ha sustituido el logo de Obama por el de los Panteras Negras, grupo de color continuador de las ideas de Malcolm $\mathrm{X}$ al que se acusa de apoyar a Obama y de obtener votos favorables mediante la intimidación. El programa de Obama es visto como un condensado proyecto de intromisión estatal y como un acrecentamiento del gasto público. "SOCIALISM", entendido en el sentido americano, viene a decir: Obama nos conduce al colectivismo con un gasto social descontrolado que tenemos que cubrir con nuestros impuestos. Uno de los eslóganes conservadores es: ¡sublevación contra el socialismo! ("Revolt against socialism”).El intervencionismo estatal está considerado en EEUU como la bestia negra contra su sistema de libertades individuales y sus ciudadanos suponen que aquellos campos que sean absorbidos por la Administración se verán irremisiblemente deteriorados. Según Jerry Bowyer, colaborador de la cadena CNBC, el ideario de Obama se basa en nacionalizar la economía y manipular el proceso democrático. "FASCISM" es la visión del Tea Party según la cual Obama es un dictador. La palabra, por tanto, equivale a totalitarismo y tiranía. Esta es la razón por la que invocan el arcaico patriotismo y convocan a la acción: utilizando gorras, vistiendo camisetas o repartiendo pegatinas todo ello con este eslogan 30 "1776 Our Founding Fathers took a stand against tyranny! Now it is our turn! ".

\footnotetext{
${ }^{30}$ En 1776, nuestros Padres Fundadores se declararon (a favor de tomar las armas para luchar) contra la tiranía. ¡Ahora es nuestro turno! Como podemos comprobar la cultura de las armas está, por diferentes y complejas razones, fuertemente asentada en Estados Unidos y tiene gran relevancia en el imaginario colectivo.
} 
Estas reacciones derechistas no son nuevas, durante la campaña presidencial Obama tuvo que disculparse por haber afi rmado al referirse a las pequeñas localidades que representan la América rural:

It's not surprising then they get bitter. They cling to guns, or religion, or antipathy to people who aren't like them, or anti-immigrant sentiment or anti-trade sentiment as a way to explain their frustrations. ${ }^{3 l}$

\section{F) Grado 6: Diatriba no exenta de odio}
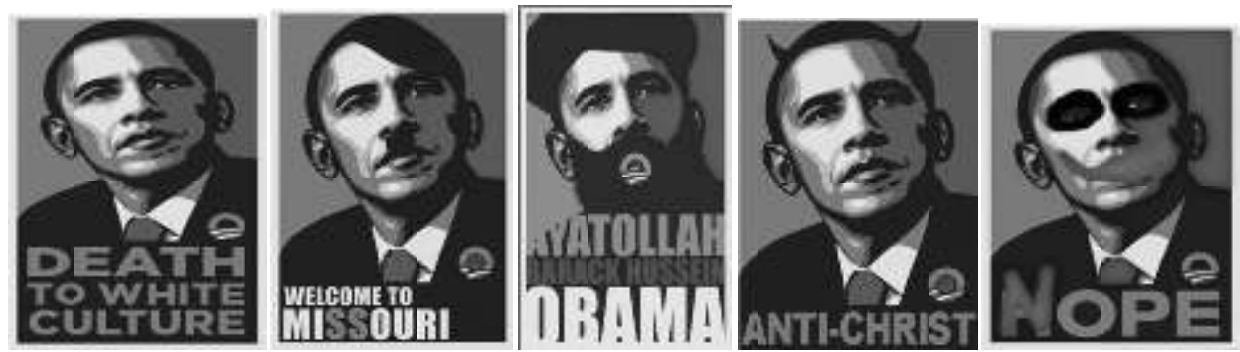

Discurso que induce a la confrontación y al odio (hateful discourse). La cadena de televisión conservadora Fox News ha llegado al extremo de promocionar movilizaciones contra Obama, como las denominadas 'Tea Parties'. Una de las más notorias fue cuando llenaron el Lincoln Memorial en Washington DC desde donde acusaron a Obama de racismo contra los blancos; exactamente en el mismo lugar donde años antes Martin Luther King pronunció su más famoso discurso. Un acto que se inició con el juramento a la bandera y el canto del himno nacional. El analista de la FOX Glenn Beck se ha convertido en un gurú que defi ende un mensaje ultrarreligioso, ultraconservador y anti-Obama. Este presentador populista acusa al presidente de odiar a los blancos y a su cultura: "Obama has a hatred of white people, of white culture”. Ha llegado a culparle de practicar políticas incendiarias y el grado de confrontación ha llegado a tal punto que La Casa Blanca anunció que ya no tratará a la cadena de televisión propiedad de Rupert Murdoch como a un medio de comunicación, por considerarla destructiva para el crecimiento de América a largo plazo, sino como a un rival político, es decir, exactamente igual que al Partido Republicano.

En“Welcome to Missouri”, (bienvenido a Missouri), se recalca en el lema las letras SS y su referente nazi al que se añade la modifi cación de la imagen incorporándole fl equillo y bigote hitleriano. El contexto se refi ere a la acusación de abuso de autoridad y de intento de intimidación de los oponentes de Obama. Se basa en las declaraciones públicas realizadas por el gobernador Matt Blunt ${ }^{32}$ :

\footnotetext{
${ }^{31}$ No es sorprendente entonces que estén amargados. Se aferran a las armas, a la religión o la aversión hacia las personas que no son como ellos, o a la anti-inmigración o la oposición al libre-comercio como una forma de explicar sus frustraciones. http://www.telegraph.co.uk/news/worldnews/1584997/Barack-Obama$\underline{\text { regretscomments-about-bitter-small-town-Americans.html }}$

${ }^{32}$ Lo que el senador Obama y sus ayudantes están haciendo es un escándalo que va más allá de las palabras, el partido que reclama ser el de Thomas Jefferson está abusando del sistema de justicia y de las instituciones
} 
What Senator Obama and his helpers are doing is scandalous beyond words, the party that claims to be the party of Thomas Jefferson is abusing the justice system and offi ces of public trust to silence political criticism with threats of prosecution and criminal punishment.

Otro activista conservador es el locutor de radio y comentarista político Rush Limbaugh que se permite declaraciones de esta índole 33 : "Soros has bought the Democrat Party and Barack Hussein Imam Obama”; porque consideran que no debe promover un diálogo directo con Irán y porque afi rman que simpatiza con la causa Palestina y no apoya a Israel incondicionalmente, con toda intencionalidad se ha colocado el logo tapando su boca. En EE.UU. la intolerancia más radical casi siempre está relacionada con cuestiones religiosas de ahí la acusación fanática de que Obama es musulmán y el "ANTI-CHRIST": "Obama is the Antichrist, oust Obama!” (¡Obama es el anticristo, derroquemos a Obama!) Un grupo intervenido por el FBI en Michigan llamado Hutaree exhibía en su página Web a sus miembros armados y en traje de camufl aje. Esta agrupación sigue al pie de la letra las enseñanzas de la Biblia en pasajes como este: "We believe that one day, as prophecy says, there will be an Anti-Christ. (...) Jesus wanted us to be ready to defend ourselves using the sword. " ${ }^{34}$ Declaración que lleva implícita la posibilidad del uso de la violencia. Obama con el rostro pintado de blanco, como advierte Skeeter Sanders en su artículo del 7 de Marzo de 2010, puede ser interpretado como un discurso gráfi co racista ${ }^{35}$ : "That caricature of the nation's fi rst black president in White face-employed frequently by Tea Party movement activists - has been denounced by critics of the Tea Party movement as racially offensive"; los ojos en negro y los labios simulando los de un payaso son otras manipulaciones del rostro a las que se le ha sometido para caracterizarlo como la personifi cación del Joker que iconológicamente es la representación preclara del caos y del crimen en contraposición al orden y la justicia que encarna Batman en "The Dark Knight”. Se ha superpuesto una "N" de color rojo a la letra hache de "hope". En consecuencia, la palabra "nope" resultante es el contexto en el que puede inscribirse un "no" rotundo al malvado y perverso Obama al que, como en el cómic, hay que combatir.

\footnotetext{
públicas fi deicomisarias para silenciar la crítica política con amenazas de enjuiciamiento y de sanción penal. Ver en [https://snappedshot.com/archives/2899-Missouri-Governor-Responds-To-Obama-Truth-Squads.html]

${ }^{33}$ Soros ha comprado al partido Demócrata y al imán islámico Barack Husein Obama. George Soros es un millonario norteamericano de origen húngaro que apoyó la campaña de Obama por lo que los conservadores consideran al presidente como una de sus marionetas y al propio tiempo lo acusan de ser musulmán.

${ }^{34}$ Creemos que un día, como afi rma la profecía, llegará un Anticristo. Jesús quiere que estemos preparados para defendernos usando nuestras espadas. Esta declaración es un fi el refl ejo de la cultura de las armas "gun culture" propia de las milicias y de otros movimientos cercanos al extremismo político. Véase en: http://www. cbsnews.com/8301-504083_162-20001341-504083.html

${ }^{35}$ Esta caricatura del primer presidente negro de la nación con el rostro embadurnado de blanco, empleada con frecuencia por los activistas del movimiento Tea Party ha sido denunciada por los críticos de esta corriente como racialmente ofensiva. Tomado de http://readersupportednews.org/pm-section/78-78/1185-gop-caughtplottingjoe-mccarthy-style-fear-campaign-against-obama-democrats
} 


\section{G) Grado 7: Retórica Violenta}

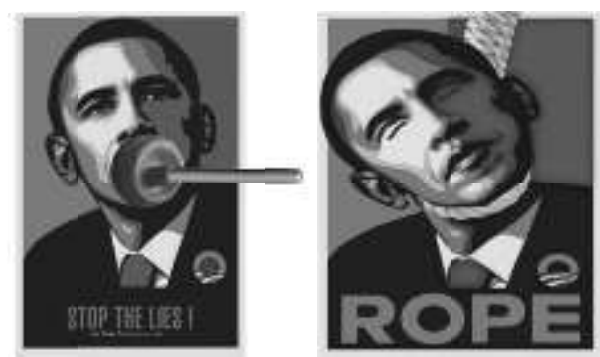

Retórica violenta (violent rhetoric). Estamos refiriéndonos a enunciados que implícitamente llaman a la acción. La defi nimos anteriormente como el uso de expresiones o imágenes que puedan incitar a la violencia real aunque sus posibilidades sean remotas. La acción de tapar la boca de Obama, porque hay que impedir que diga mentiras, utilizando para ello un desatascador (plunger) implica una energía física violenta. Se trata ya de algo más que grafi smos, palabras y lemas. Mucho más preocupante es la información aparecida en una página $\mathrm{Web}^{36}$ donde se alude expresamente a otro sitio de Internet titulado 'Obama Is A Bitch' y se pone especial énfasis en recalcar que las palabras citadas son estrictamente literales (verbatim):

The problem with Americans is we sometimes don't realize who the enemy is as quickly as we should!!! Polls taken during World War II indicated the majority of Americans identifi ed "the uncontrolled Negro" as "a greater danger to the nation" than "a Jap soldier" and more dangerous than "a Nazi" throughout the entire war!!! Funny how we elected a Communist, Muslim, Racist, Liberal Negro Nazi as president!!!

Tras declaraciones como ésta, el cartel "ROPE" evoca de manera dramática los linchamientos y las ejecuciones de negros llevadas a cabo por el Ku Klux Klan (KKK) organización que promovía la xenofobia y la supremacía de la raza blanca. Entendido este último término como la descripción de una ideología política que promueve el dominio social y político de los blancos.

\section{H) Grado 8: El discurso destructivo}

Por razones de extensión hemos dejado de considerar una addenda fi nal que, aunque no tiene una relación, estrictamente directa, con el póster "hope”, que es nuestro objeto de estudio, viene a representar el remate del asta de la bandera que se muestra en el chiste, ejemplifi ca de manera ostensible un grado superior: el discurso destructivo (grado 8) al que hemos califi cado como: en el visor está el objetivo (in the crosshairs is the target). Dejamos, caveat lector, estas tres imágenes: del póster Hope como un plato para el tiro ( $a$

\footnotetext{
${ }^{36}$ ¡El problema con los estadounidenses es que a veces no se dan cuenta de quién es el enemigo tan rápido como deberían! Las encuestas llevadas a cabo durante la segunda guerra mundial indican que la mayoría de los estadounidenses identifi caban al negro (negrata /ofensivo) incontrolado como un peligro mayor para la nación que el de un soldado japonés; y más peligroso que un nazi; durante el transcurso de toda la guerra! ¡Es curioso cómo se ha elegido a un comunista, a un musulmán, a un racista, a un negro liberal y nazi como presidente! Ver en [ http://hangoverhelper.blogspot.com/2009/10/read-and-fucking-weep.html]
} 
clay pigeon shooting), del logotipo personal como una diana (shooting target) y del rostro de Obama como un objetivo real fi gurado.
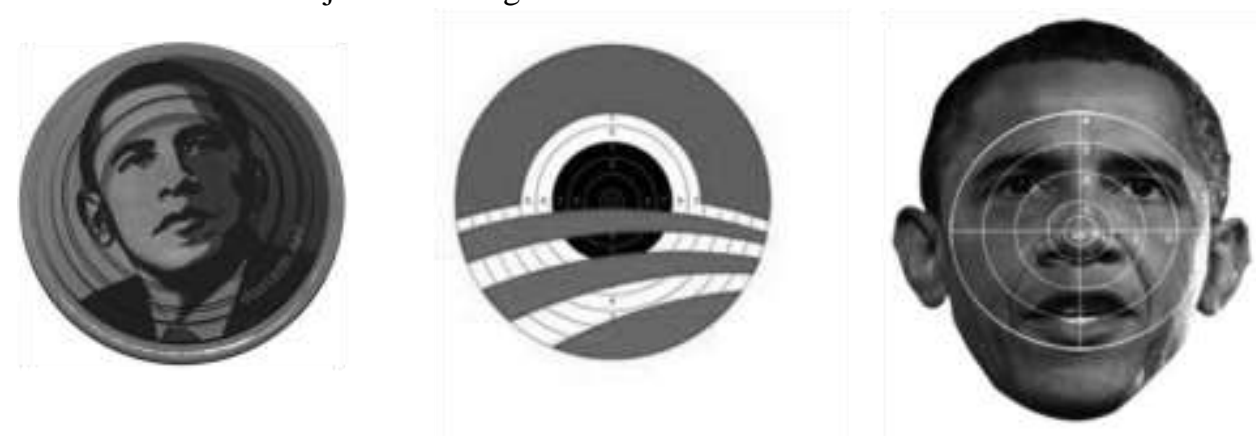

\section{CONCLUSIONES}

El cartel "HOPE" de Barack Obama confi gura un discurso electoral que posee su propia identidad, como foco contextual o género, determinada por el propósito estético, persuasivo y socializador que lo impulsa. Su estudio puede ser abordado desde la Teoría de la Relevancia como un caso práctico que ayude a complementar los abundantes estudios teóricos, en muchos casos, saturados de metalenguaje. Permite ser catalogado siguiendo la taxonomía del modelo escripto-icónico desarrollado por Yus Ramos (1997) como un patrón de comunicación dialógica, verbal, intencional y de máxima efi cacia comunicativa.

Enfocado como un producto de marketing político, es decir, como estrategia comunicativa del candidato, constituye una imagen corporativa personal, efi caz y declinable que ha conseguido traspasar sus usos específi cos hasta convertirse en un objeto artístico de carácter icónico razón por la que hoy está expuesto en un museo.

$\mathrm{Su}$ dimensión retórica unida al enorme potencial comunicativo demostrado como publicidad viral ha favorecido la aparición de un sinnúmero de versiones paródicas o ideas contagiosas que han afl orado fundamentalmente en Internet por lo que este medio se erige en un amplio campo de estudio en el que convergen diferentes posibilidades de investigación pragmática.

Sostenemos que una de las posibles aplicaciones de la teoría de la relevancia es la explicación de los fenómenos paródicos virales o epidemiológicos y de humor gráfi cosatírico en política. La aparición de réplicas, por parte de los receptores al mensaje original, propicia la creación de una suerte de discurso circular de carácter heterogéneo, en el que aparecen gran variedad de registros y diferentes actitudes ideológicas. La comunicación así comprendida trabaja como un sistema (un proceso) en el que los interlocutores participan mostrando con sus mensajes un comportamiento sociocultural que intuye el traductorintérprete en una comunicación de segundo orden, en la que pretende ser cuasi-neutral, pero que en su origen ha sido fruto de conductas comunicativas dinámicas, individuales y diversas que propician esa epidemiología de las representaciones de la que nos habla Dan Sperber (1996) y que pueden estar distanciadas cronológicamente favoreciendo, por tanto, un cierto grado de diacronía comunicativa. 
Desde la presunción de que las representaciones paródicas del cartel son usos distorsionados y ecoicos del original hemos refl exionado sobre el mensaje interesado y el lenguaje hostil en política, acabando en la consideración de que las réplicas de los receptores conforman una especie de orquesta cultural donde no hay director ni partitura. Cada uno toca poniéndose de acuerdo con el otro como en una ruptura de la lógica o metalepsis. Sólo un observador exterior, es decir, un investigador de la comunicación que haga el papel de intérprete, puede elaborar progresivamente una partitura escrita, que sin lugar a dudas constituye una tarea altamente compleja.

Representando este papel hemos seleccionando en la Red un pequeño corpus y con él hemos realizado una propuesta de aproximación categorizadora sobre los diferentes grados del discurso con intencionalidad política y su relación con la violencia desde la óptica de que la materia prima de la cultura está constituida por una mezcolanza de representaciones mentales y personales y de otras públicas o compartidas. Esta combinación facilita las prácticas y las respuestas emocionales así como un juego de sinergias que las combinan localmente de maneras poco predecibles desde una clave caológica. Apreciando y contextualizando esa rica pluralidad de mensajes que no pertenecen a un discurso homogéneo sino a una variedad amplia de situaciones y registros creemos que hemos podido llegar a refl ejar valiosos componentes del patrimonio político-cultural de una nación.

\section{REFERENCIAS BIBLIOGRÁFICAS:}

B , G., $\square \square \square \square .1987$. La nueva comunicación. Selección y estudio preliminar de Yves Winkin. Kairós. Barcelona.

F P , C. 2008. La importancia de la comunicación no verbal en la confi guración de la imagen corporativa. ICONO $14 \mathrm{~N}^{\mathrm{o}} 11$.

G R , A. Obama: el político moderno. 10 claves para comprender el éxito de la nueva política. i\&m. investigación y marketing. Aedemo ( $n^{\circ} 99$. Junio 2008) (versión pdf) disponible en [http://gutierrez-rubi.es/wp-content/uploads/2008/07/ Obama_el_politico_moderno.pdf ]

H P , S. 1996. La retórica en el lenguaje publicitario alemán. Revista de Filología Alemana $n^{\circ}$ 4, 223-234. Servicio de Publicaciones UCM. Madrid.

L F , V. 2010. “Traducción y relevancia: ¿qué quiere decir 'semejanza interpretativa' en traducción?" en Perdu Honeyman, N. Cambio de dimensiones en traducción y comunicación. Almería: Editorial Universidad de Almería, pp. 47-71.

P B , S.2004. Conceptos y aplicaciones de la Teoría de la Relevancia. Arco Libros SL. Madrid.

P Y ～J.M. 1989. Teoría del lenguaje literario. Madrid: Cátedra.

R T, M.A. Caracterización del lenguaje político. cvc.cervantes.es/literatura/ aispi/pdf/16/16_009.pdf 
S ,D. \& W , D. 1986, 1995. Relevance: Communication and Cognition, Oxford:Blackwell.

S , D. 1996.Explaining Culture: A Naturalistic Approach. Oxford: Blackwell.

T , K. 1994. Advertising Language. Londres: Routledge.

T S , F. 2001. La Teoría de la Relevancia como base para una nueva interpretación de la comunicación. Euphoros, nº 3, pp. 221-232

U F , R. 2006. Núcleos semánticos y núcleos pragmáticos en el lenguaje publicitario. Actas del XXXV Simposio Internacional de la Sociedad Española de Lingüística, pp. $1869-1887$

V Z , A. \& H F , D. A. 2008."La estrategia Obama: La construcción de una marca triunfadora en la política electoral", en Revista Latina de Comunicación, 63, en http://www.ull.es/publicaciones/latina/08/alma03/11_obama.pdf

W, P, . . 1987. Teoría de la comunicación humana. Interacciones, patologías y paradojas, 6a Edición, Editorial Herder. Barcelona, 1987

W , D. 2011."Parallels and differences in the treatment of metaphor in Relevance theory and cognitive linguistics". Studia Linguistica, vol. 128, pp. 195-213.

Y M , R. 2006. Límites éticos del mensaje persuasivo en la comunicación política. Zer: Revista de estudios de comunicación = Komunikazioikasketenaldizkaria, $\mathrm{N}^{\circ}$. 20.

Y R , F. 1997. La interpretación y la imagen de masas. Alicante: Diputación de Alicante, Instituto Juan Gil-Albert.

Y R , F. 2001. Ciberpragmática. El uso del lenguaje en Internet. Barcelona. Ariel. 2001.

\section{REFERENCIAS DE LAS IMÁGENES}

Obama Hope for sale

[http://myrtus.typepad.com/myrtus/2008/07/obama-hope-for.html]

El tatuaje del póster de Obama procede de [http://blogs.villagevoice.com/ streetculture/2009/01/the_most_ghetto.php]

Pierce Brosnan, el James Bond de los 90, vistiendo la camiseta de Obama. [http://www.

fi bers.com/blog/celebrities-caught-wearing-barack-obama-t-shirts/ ]

ShepardFairey posa ante su famoso retrato ocupando todo un muro [http://www. elnuevoherald.com/2010/09/24/808649/el-artista-del-retrato-hope-de.html]

Mujer contemplando el póster en el Smithsonian National Portrait Gallery [http://www. telecinco.es/informativos/fresaacida/noticia/1372122/1372122] 
Obama change [http://www.fulcrumgallery.com/Shepard-Fairey/RAREObamaCampaign-Poster-CHANGE_644605.htm ]

Obama progress [http://www.shepardfaireyprints.info/print8834_obama_progress fairey print.html?cur=GBP ]

Speaking for recessions. Diminished hope..., del dibujante Steve Breen. [http://www. franklinnow.com/blogs/communityblogs/82465497.html]

Tea Party Ogre cartoon del dibujante Adam Zyglis[http://politicalhumor.about.com/ od/politicalcartoons/ig/Tea-Party-Cartoons/Tea-Party-Ogre.htm]

Patrick Blower's Livedraw Review of 2009. In this brilliant 'best of 2009' Livedraw cartoon, the Guardian's Patrick Blower looks back at a year when America looked to Barack Obama for change, and bankers looked to taxpayers for bailouts. [http:// jeffreyhill.typepad.com/english/2009/12/patrick-blowers-cartoon-review-of-2009. html]

La página de Rene Wanner ofrece 149 imágenes relacionadas con el póster de ShepardFairey aunque sólo unas pocas nos han resultado de interés para nuestro estudio, concretamente: "Hope", "Chope”, "Uhhh”, "Hype”, "McDaddy", “Arab”, "Nope", "Taupe", "Racist", "Socialism". [http://www.posterpage.ch/exhib/ex216oba/ ex216oba.htm ]

Hope $=$ Disonancia isotópica sobre guerra de Afganistán [http://www.justicewithpeace. org/obama-mit-oct23 ]

Hope $=$ blah, blah... [http://cristyli.blogspot.com/2008_10_01_archive.html]

Hope $=$ Opss [http://deceiver.com/2009/03/20/president-obama-gets-award-fromthepress-who-are-not-allowed-to-cover-it/ ]

Hope $=$ The Audacity of Inexperience [http://cristyli.blogspot.com/2008_06_01_archive. html]

Hope $=$ Cope $[\mathrm{http}: / /$ the189.com/design/art/the-obama-cope-poster/ ]

Hope $=$ Nope [http://iowasnewzliter.blogspot.com/2008_07_01_archive.html ]

Hope $=$ Taxes [http://www.sodahead.com/united-states/2011-taxes-are-you-readyforthis/blog-385927/ ]

Hope $=$ Grope $[$ http://themadjewess.wordpress.com/2009/07/10/i-did-not-look-atthatgirl-with-lust-says-emperor-hussein-obama/ ]

Hope $=$ Torture [http://mediamonarchy.blogspot.com/2009 08 01_archive.html ]

Hope $=\mathrm{T}-\mathrm{Bag}$ against Obama

[http://steynian.wordpress.com/2009/04/16/steynian346/]

Hope $=$ Abortion [http://www.jillstanek.com/stanek-columns/ ]

Hope $=$ Liar [http://westernfrontamerica.com/2008/12/15/liarelect-death-america/]

Hope $=$ Just What in the Hell is Barack Obama? [http://www.barking-moonbat.com/ index.php/weblog/the only_obama_poster_you_need/] 
Hope $=$ The unqualified Barack Obama [http://www.brokencountry.com/index. php/2009/01/20/the-unqualifi ed-barack-obama/]

Hope $=7 \$$ Dollars Gas [http://www.freerepublic.com/focus/news/2463127/posts]

Hope $=$ Coke [http://www.berezobama.com/?paged $=3$ ]

Hope $=$ Dope [http://themarkvolta.wordpress.com/ ]

Hope $=$ Socialism [http://nicedeb.wordpress.com/2008/09/25/obama-threateningtvstations-again/]

Hope $=$ Communist [http://gatsbysmonologue.wordpress.com/page/2/]

Hope $=$ Death to white culture [http://lackofreality.com/]

Hope $=$ Welcome to Missouri [http://snappedshot.com/archives/2899MissouriGovernor-Responds-To-Obama-Truth-Squads.html ]

Hope $=$ Ayatollah Barack Hussein Obama! [http://pichaus.com/obama-mullahposterpresident-@a04d3f113e7c8a526d619a781f7369bf/ ]

Hope $=$ Antichrist [http://obamaisabitch.wordpress.com/2009/10/22/721/]

Hope $=$ Nope/Jocker [http://gossipinbitches.com/tag/birth-certifi cat/]

Hope $=$ Rope [http://hangoverhelper.blogspot.com/2009/10/read-and-fucking-weep. html]

Obama logo in the cross hairs [http://fredfryinternational.blogspot.com/2008/08/ reimagined-sportsmen-for-obama-campaign.html]

In the Line of Ire. Can you shoot an Obama target? [http://www.slate.com/ $\underline{\mathrm{id} / 2263595 /]}$ 


\section{Please use this identifier to cite or link to this item:}

http://hdl.handle. net/10835/2086

Full metadata record

DC Field

Value

Language

dc.contributor.author Balsera Fernández, Manuel - dc.date.accessioned 2013-

04-04T18:58:15Z - dc.date.available 2013-04-04T18:58:15Z -

dc.date.issued 2012 - dc.identifier.issn 1578-3820 - dc.identifier.uri

http://hdl.handle.net/10835/2086 - dc.description.abstract En este artículo

nos proponemos examinar el es_ES

cartel "HOPE" de Barack Obama, entendido

como un discurso electoral icónico-verbal y

artístico a la luz de la Teoría de la Relevancia de

Sperber \& Wilson (1986, 1995, 1998, 2002;

Wilson \& Sperber 2002; Sperber \& Wilson, 2012) considerada como una de las más

fructíferas para estudiar la transmisión de mensajes comunicativos multimodales. Para su descripción, análisis e interpretación recurriremos al concurso de otras disciplinas y, fi nalmente, trataremos de establecer un diálogo ecoico-orquestal con otras representaciones mentales de naturaleza política y

propagandística no afín como réplicas culturales del original.

dc.publisher Universidad de Almería. es_ES dc.source Odisea :

Revista de Estudios Ingleses. Número es_ES

13, Enero-Diciembre 2012

dc.subject Pragmática es_ES dc.subject Relevancia es_ES

dc.subject Modularidad es_ES dc.subject Publicidad política

es_ES dc.subject Barack Obama es_ES dc.subject

Representaciones paródicas es_ES

dc.subject Violencia

es_ES 


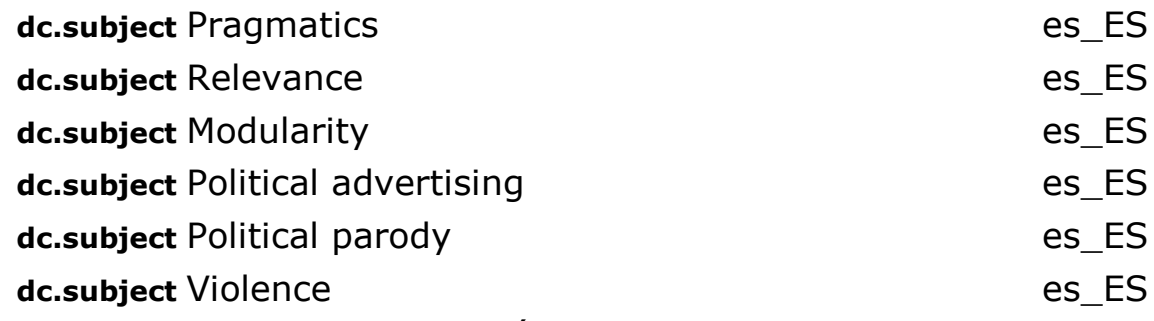

dc.title Variaciones pragmáticas del discurso electoral: es_ES El caso del "HOPE" de Barack Obama.

dc.title.alternative Pragmatic variations of electoral discourse: The es_ES poster "Hope" of Barack Obama.

dc.type info:eu-repo/semantics/article es_ES

dc.relation.publisherversion http://www.ual.es/odisea/Odisea13_Balsera.pdf es_ES dc.rights.accessRights info:eu-repo/semantics/openAccess es_ES Appears in Collections: $\underline{\text { Odisea : Revista de Estudios Ingleses. Número }}$ 